\title{
Angiotensin II as an Inducer of Atherosclerosis: Evidence from Mouse Studies
}

Maxime Pellegrin and Lucia Mazzolai*

Division of Angiology, University Hospital of Lausanne, Lausanne, Switzerland

\begin{abstract}
Mechanisms responsible for atherosclerotic plaque development, destabilization, and rupture are still largely unknown. Angiotensin II, the main bioactive peptide of renin angiotensin system, has been shown to be critically involved in the pathogenesis of atherosclerosis and vulnerable plaque. Experimental studies in hypercholesterolemic mouse models with high circulating Angiotensin II levels, provide direct evidence that Angiotensin II induces plaque vulnerability partly by $1 /$ downregulating vascular expression of anti-atherosclerotic genes and/or upregulating expression of pro-atherosclerotic genes, and 2/ skewing the systemic lymphocyte Th1/Th2 balance towards a proinflammatory Th1 response in early disease phase. Further understanding the pro-atherosclerotic mechanisms of Angiotensin II and associated signaling pathways will help to design better therapeutic strategies for reducing the burden of atherosclerotic cardiovascular disease.
\end{abstract}

Keywords: Angiotensin II; Mouse studies; Cellular and molecular mechanisms

\section{Introduction}

Atherosclerosis (ATS) is a chronic inflammatory disease characterized by formation of a plaque or lesion (also called atheroma) in the intimal layer of the arterial wall. Atherosclerotic plaque is composed of oxidized lipids and lipoproteins, inflammatory cell infiltrates, areas of cell death and fibrosis [1]. ATS is the leading cause of morbidity and mortality in developed nations. ATS is a dynamic disease evolving in time often-taking decades to develop advanced lesions responsible for clinical symptoms. Plaques may remain asymptomatic (subclinical disease), become occlusive (intermittent claudication or stable angina pectoris), or become thrombosis-prone (vulnerable) leading to athero-thrombotic events, such as myocardial infarction or stroke [2]. Pathogenesis of ATS is not yet fully elucidated; however clear evidence indicate that the Renin-Angiotensin System (RAS), and in particular its final product Angiotensin (Ang) II, play a pivotal role in atherogenesis.

The RAS is intimely involved in the maintenance of cardiovascular homeostasis, including regulation of blood pressure, blood flow, fluid volume and electrolyte balance. Secretion of renin is the first step in the RAS cascade. Renin is secreted in a regulated manner by the juxtaglomerular cells of the kidneys. Renin cleaves angiotensinogen, mainly synthesized in the liver, to form the inactive peptide Ang I. This is in turn converted by the Angiotensin Converting Enzyme (ACE) to form the biologically active peptide Ang II, the primary effector of the RAS. Ang II exerts its physiological actions through membrane-bound receptors of the G-protein coupled receptor family. The two main Ang II receptors are the Ang II receptor subtypes 1 (AT1) and 2 (AT2) which induce different signaling pathways and cellular responses. Proatherosclerotic actions of Ang II are mediated by the AT1 receptor whereas the role of AT2 in ATS is still controversial. AT1 receptor is expressed in a variety of organs, blood vessel, and in bone marrowderived cells, such as macrophages and T cells $[3,4]$.

The importance of Ang II in atherosclerotic cardiovascular disease has been widely demonstrated both indirectly and directly in humans and mouse models. Indeed, pharmacological inhibition of RAS system using ACE inhibitors or Angiotensin Receptor Blocker (ARBs) prevents or delays progression of ATS and reduces cardiovascular events in patients $[5,6]$. Along the same line, pharmacological inhibition or genetic inactivation of RAS prevents ATS development and stabilizes plaques in animal models of ATS [7-10]. Observational studies in humans have demonstrated that patients with high levels of circulating renin are at increased risk for myocardial infarction and other atherosclerotic cardiovascular events, suggesting a direct role for Ang II in promoting ATS $[11,12]$. During the past decades, specific mouse models with increased plasma concentrations of Ang II have been generated in hypercholesterolemic apolipoprotein E-deficient $\left(\mathrm{ApoE}^{-/}\right)$ and low-density lipoprotein-deficient $\left(\mathrm{LDLr}^{-/}\right)$mice, allowing study of mechanism through which Ang II promotes ATS $[13,14]$.

This review emphasizes the pro-atherosclerotic effects and underlying mechanisms of Ang II derived from mouse studies with Ang II-mediated ATS.

\section{Mouse Models of Ang II-induced Atherosclerosis}

To define the direct role of Ang II in atherogenesis, nonphysiological and physiological models have been generated in ApoE /- or LDLr ${ }^{/ /}$mice.

\section{Non-physiological model: subcutaneous infusion of Ang II}

Daugherty et al. initiated studies in which Ang II was subcutaneously and chronically infused into $\mathrm{ApoE}^{-/-}$mice for 28 days by using osmotic pumps [13]. Results showed that Ang II promoted a significant increase in the extent of atherosclerotic lesion in the thoracic aorta, and that lesions were predominantly rich in lipid-laden macrophages and lymphocytes. Of note, authors reported no significant differences

\footnotetext{
*Corresponding author: Lucia Mazzolai, Division of Angiology, Centre Hospitalier Universitaire Vaudois (Nestlé 06), Av. Pierre-Decker 5, 1011 Lausanne, Switzerland, Tel: +41-21-3140750; Fax: +41-21-3140761; E-mail: lucia.mazzolai@chuv.ch

Received April 10, 2013; Accepted May 22, 2013; Published May 25, 2013

Citation: Pellegrin M, Mazzolai L (2013) Angiotensin II as an Inducer of Atherosclerosis: Evidence from Mouse Studies. J Clin Exp Cardiolog S1: 007. doi:10.4172/2155-9880.S1-007

Copyright: (c) 2013 Pellegrin M, et al. This is an open-access article distributed under the terms of the Creative Commons Attribution License, which permits unrestricted use, distribution, and reproduction in any medium, provided the original author and source are credited.
} 
between mice infused with increasing doses of Ang II (500 compared to $1000 \mathrm{ng} / \mathrm{min} / \mathrm{Kg}$ ). Unexpectedly, mice also developed large abdominal aortic aneurysm. These vascular effects of Ang II occurred independent of blood pressure elevations or changes in plasma lipid concentration [13]. Weiss et al. also showed that subcutaneous Ang II infusion induced-hypertension (8 weeks) specifically increased plaque size, in thoracic and abdominal aorta, as well as macrophage infiltration in $\mathrm{ApoE}^{-/}$mice receiving standard chow or atherogenic diet [15]. $\mathrm{Ni}$ et al. have first demonstrated evidence of plaque vulnerability in response to Ang II infusion in ApoE-/- mice [16]. Authors reported that Ang II infusion into $\mathrm{ApoE}^{-/-}$mice not only increased plaque size confirming previous findings, but also promoted atherosclerotic plaque transformation to a more destabilized phenotype (increased macrophages and lipids, decreased collagen and smooth muscle cells content) [16]. Ang II continued to accelerate ATS in $\mathrm{ApoE}^{-/-}$mice even after discontinuation of Ang II infusion [17].

\section{Physiological model: 2-Kidneys, 1-Clip renovascular hypertension}

To study the contribution of Ang II in ATS in physiological conditions, Mazzolai et al. generated hypertensive ApoE $\mathrm{E}^{-/-}$mice with endogenously increased (two-kidney, one clip, 2K1C) Ang II production (renovascular hypertension model) [14]. The $2 \mathrm{~K}^{\mathrm{C}} \mathrm{ApoE}^{-/-}$mice are characterized by a pathophysiologically and continuously stimulated RAS with an endogenous increase in renin and consequently Ang II production secondary to unilateral renal artery clipping producing artery stenosis $[18,19]$. Contrary to models were high doses of Ang II are exogenously administered via minipumps as described above, the $2 \mathrm{~K} \mathrm{C} \mathrm{ApoE}^{-1-}$ mouse model allows studying the effect of Ang II and hypertension on ATS development/progression in a context that is very much similar to that found in humans. In fact, in the $2 \mathrm{~K} 1 \mathrm{C}$ $\mathrm{ApoE}^{-/-}$mice, increased endogenous Ang II production is achieved

\begin{tabular}{|c|c|}
\hline Pro-atheroscleotic genes & Effect of Ang II \\
\hline monocyte chemotactic protein-1 (MCP-1) & upregulation \\
\hline macrophage-colony stimulating factor (M-CSF) & upregulation \\
\hline endothelial-selectin (E-selectin) & upregulation \\
\hline intercellular adhesion molecule-1 (ICAM-1) & upregulation \\
\hline vascular cell adhesion molecule-1 (VCAM-1) & upregulation \\
\hline inducible nitric oxide synthase (iNOS) & upregulation \\
\hline cyclooxygenase-2 (COX-2) & upregulation \\
\hline tumor necrosis factor- $\alpha$ (TNF- $\alpha$ ) & upregulation \\
\hline interleukin-6 (IL-6) & upregulation \\
\hline interleukin-1 $\beta$ (IL-1 $\beta)$ & upregulation \\
\hline transforming growth factor $\beta 1$ (TGF- $\beta 1$ ) & upregulation \\
\hline $\begin{array}{l}\text { regulated upon Activation, Normal T cell Expressed and } \\
\text { Secreted (RANTES) }\end{array}$ & upregulation \\
\hline monocyte chemoattractant protein-1 (MCP-1) & upregulation \\
\hline C-C chemokine receptor type 1 (CCR1) & upregulation \\
\hline C-C chemokine receptor type 2 (CCR2) & upregulation \\
\hline C-C chemokine receptor type 3 (CCR3) & upregulation \\
\hline granulocyte colony-stimulating factor (G-CSF) & upregulation \\
\hline granulocyte macrophage colony-stimulating factor (GM-CSF) & upregulation \\
\hline interleukin-12 IL-12 (P40) & upregulation \\
\hline macrophage inflammatory protein $1-\alpha(\mathrm{MIP}-1 \alpha)$ & upregulation \\
\hline interferon- $\mathrm{\gamma}(\mathrm{IFN}-\mathrm{\gamma})$ & Upregulation \\
\hline Anti-atheroscleotic genes & Effect of Ang II \\
\hline peroxisome proliferator-activated receptor- $\alpha$ (PPAR- $\alpha$ ) & Downregulation \\
\hline peroxisome proliferator-activated receptor- $\gamma$ (PPAR- $\gamma)$ & downregulation \\
\hline
\end{tabular}

Table 1: Effects of Angiotensin II on pro-atherosclerotic and anti-atherosclerotic genes expression in mouse aorta $[16,20,21]$. through stimulation of renal renin secretion, as it occurs in humans, thus taking into account all the physiological regulatory mechanisms. Results revealed that $2 \mathrm{~K} 1 \mathrm{C} \mathrm{ApoE}-1-$ mice presented increased lesion surface compared to normotensive $\mathrm{ApoE}^{-/-}$mice. However, extent of increased lesion surface was comparable to that observed in similarly hypertensive $\mathrm{ApoE}^{-/-}$mice but with normal circulating Ang II levels (1-kidney, 1-clip [1K1C] model) [14]. Nevertheless, 2K1C mice developed more advanced and vulnerable plaques than $1 \mathrm{~K} 1 \mathrm{C}$ mice (thinner fibrous cap, larger lipid core, increased macrophage content and decreased smooth muscle cells), confirming the hypothesis that Ang II mediates ATS independently of its hemodynamic effects but via a direct vascular effect.

\section{Cellular and Molecular Mechanisms Responsible for the Pro-atherosclerotic Role of Ang II}

\section{Ang II modulates pro-atherosclerotic genes expression in vascular wall}

Several studies have shown that Ang II increases expression of pro-atherosclerotic and/or decreases expression of anti-atherosclerotic genes in the aorta (Table 1). For example, Tham et al. reported a downregulation of the anti-inflammatory genes PPAR- $\alpha$ and PPAR- $\gamma$, and an upregulation of pro-inflammatory genes such as the MCP-1, the M-CSF, the E-selectin, the ICAM-1, the VCAM-1, the iNOS, and the COX-2 through a nuclear factor-kappaB-dependent pathway in aorta from $\mathrm{ApoE}^{-/-}$mice infused with Ang II [20]. Increased expression of other pro-inflammatory cytokines in response to Ang II has also been shown in aorta and culture of explanted aorta from mice with Ang IIinduced ATS [16,21]. More recently, it has been shown that Ang II upregulated extracellular matrix metalloproteinase inducer (EMMPRIN) expression in aortic plaques from $\mathrm{ApoE}^{-/-}$mice, which could play a role in plaque destabilization [22].

\section{Ang II induces Th1/Th2 imbalance}

Inflammatory cells, including CD4 T lymphocytes, are commonly found in ATS plaque during all stages of the disease [1]. CD4 ${ }^{+} \mathrm{T}$ cell subtype Th1 (pro-inflammatory cells) plays a major role in ATS while the role of $\mathrm{CD}^{+} \mathrm{T}$ cell subtype Th2 (anti-inflammatory cells) is still unclear [1]. Mazzolai et al. investigated for the first time the specific role of Th1/Th2 balance in Ang II-induced ATS [14]. Results showed that IFN- $\gamma$ production (the Th1 signature cytokine) from spleen lymphocytes was stimulated in $\mathrm{ApoE}^{-/-} 2 \mathrm{~K} 1 \mathrm{C}$ one week after renal artery clipping whereas IL- 4 production (the Th2 signature cytokine) remained unchanged [14]. These findings indicate that Ang II skews the Th1/Th2 balance towards a pro-inflammatory Th1 profile in the early phase of ATS process, which may induce plaque vulnerability.

\section{Other mechanisms}

Recent studies using pharmacological or genetic approaches in Ang II-infused hypercholesterolemic mice, showed that numerous factors/proteins are involved in Ang II-induced ATS, including myeloid differentiation factor 88 (a mediator of signaling cascade that directly influences leukocytes involved in innate immunity and has indirect effects on adaptive immunity) [23], endothelin-1 [24], or receptor-associated protein (a regulator of low density lipoprotein receptor-related protein 1) [25]. Endothelial dysfunction is a critical element in the pathogenesis of atherosclerotic disease. Impaired aortic endothelium-dependent relaxation as well as decreased eNOS protein phosphorylation has been recently demonstrated in $\mathrm{ApoE}^{-/-}$miceinfused Ang II [26]. 


\section{Conclusions and Perspectives}

Mouse models with high circulating Ang II levels provide direct evidence that Ang II is a local mediator of plaque development and vulnerability. Modulation of Th1/Th2 phenotype appears to be a major downstream atherosclerotic mechanism of Ang II. Further research is needed to determine the time course of Th1/Th2 modulation in ATS process.

Th17 has been recently identified as the third CD4 T cell subset, and has been suggested to play an important role in Ang II-induced ATS [27]. However, no experimental data are available yet to substantiate this hypothesis.

Similarly, to CD4 T cells, macrophages can polarize into two different subsets: classically pro-inflammatory M1 macrophages, driven by Th1 cytokines, or alternatively anti-inflammatory M2 macrophages, driven by Th 2 cytokines. Although recent evidence indicates that the macrophage polarization balance affects pathogenesis, evolution, and complications of ATS [28], its specific implication in Ang II-induced ATS is unknown.

In conclusion, although there are good experimental proofs demonstrating a pro-atherosclerotic role of Ang II, the precise mechanisms whereby Ang II exerts its actions need further clarification. Ang II-dependent signaling pathways may refer to a complex and multi factorial process including, at least in part, the involvement of various immuno-inflammatory cell types, and a pro-and anti-inflammatory cytokines network. More work is needed to define the specific networks of pathways activated by Ang II.

\section{Clinical Applications}

A better understanding of cellular and molecular mechanisms underlying how Ang II mediates atherosclerosis and plaque vulnerability may help develop new and more selective therapeutic strategies aiming at preventing Ang II-related atherosclerotic cardiovascular disease.

Results reported in mouse studies, if confirmed in clinical studies, should have clinical implications. In fact, hypertensive or nonhypertensive patients presenting with clinical or subclinical atherosclerosis would benefit from pharmacological blockade of key pro-atherosclerotic Angiotensin II-dependent signaling pathways.

\section{References}

1. Ketelhuth DF, Hansson GK (2011) Cellular immunity, low-density lipoprotein and atherosclerosis: break of tolerance in the artery wall. Thromb Haemost 106: $779-786$

2. Ylä-Herttuala S, Bentzon JF, Daemen M, Falk E, Garcia-Garcia HM, et al. (2011) Stabilisation of atherosclerotic plaques. Position paper of the European Society of Cardiology (ESC) Working Group on atherosclerosis and vascular biology. Thromb Haemost 106: 1-19.

3. Billet S, Aguilar F, Baudry C, Clauser E (2008) Role of angiotensin II AT1 receptor activation in cardiovascular diseases. Kidney Int 74: 1379-1384.

4. Lemarié CA, Schiffrin EL (2010) The angiotensin II type 2 receptor in cardiovascular disease. J Renin Angiotensin Aldosterone Syst 11: 19-31.

5. Volpe M (2012) Should all patients at high cardiovascular risk receive reninangiotensin system blockers? QJM 105: 11-27.

6. Patarroyo Aponte MM, Francis GS (2012) Effect of Angiotensin-converting enzyme inhibitors and Angiotensin receptor antagonists in atherosclerosis prevention. Curr Cardiol Rep 14: 433-442.

7. Lu H, Rateri DL, Feldman DL, Jr RJ, Fukamizu A, et al. (2008) Renin inhibition reduces hypercholesterolemia-induced atherosclerosis in mice. J Clin Invest 118: 984-993.

8. Suganuma E, Babaev VR, Motojima M, Zuo Y, Ayabe N, et al. (2007) Angiotensin inhibition decreases progression of advanced atherosclerosis and stabilizes established atherosclerotic plaques. J Am Soc Nephrol 18: 2311 2319 .

9. Wassmann S, Czech T, van Eickels M, Fleming I, Böhm M, et al. (2004) Inhibition of diet-induced atherosclerosis and endothelial dysfunction in apolipoprotein $\mathrm{E}$ angiotensin II type 1A receptor double-knockout mice. Circulation 110: 3062 3067

10. Lu H, Balakrishnan A, Howatt DA, Wu C, Charnigo R, et al. (2012) Comparative effects of different modes of renin angiotensin system inhibition on hypercholesterolaemia-induced atherosclerosis. $\mathrm{Br} J$ Pharmacol 165: 20002008.

11. Chrysochou C, Kalra PA (2009) Epidemiology and natural history of atherosclerotic renovascular disease. Prog Cardiovasc Dis 52: 184-195.

12. Piecha G, Wiecek A, Januszewicz A (2012) Epidemiology and optimal management in patients with renal artery stenosis. J Nephrol 25: 872-878.

13. Daugherty A, Manning MW, Cassis LA (2000) Angiotensin II promotes atherosclerotic lesions and aneurysms in apolipoprotein E-deficient mice. J Clin Invest 105: 1605-1612.

14. Mazzolai L, Duchosal MA, Korber M, Bouzourene K, Aubert JF, et al. (2004) Endogenous angiotensin II induces atherosclerotic plaque vulnerability and elicits a Th1 response in ApoE-/- mice. Hypertension 44: 277-282.

15. Weiss D, Kools JJ, Taylor WR (2001) Angiotensin II-induced hypertension accelerates the development of atherosclerosis in apoE-deficient mice. Circulation 103: 448-454

16. Ni W, Kitamoto S, Ishibashi M, Usui M, Inoue S, et al. (2004) Monocyte chemoattractant protein-1 is an essential inflammatory mediator in angiotensin II-induced progression of established atherosclerosis in hypercholesterolemic mice. Arteriosclerosis, thrombosis, and vascular biology 24: 534-539.

17. Cha J, Ivanov V, Ivanova S, Kalinovsky T, Rath M, et al. (2010) Evolution of angiotensin II-mediated atherosclerosis in ApoE KO mice. Molecular medicine reports 3: $565-570$.

18. Wiesel P, Mazzolai L, Nussberger J, Pedrazzini T (1997) Two-kidney, one clip and one-kidney, one clip hypertension in mice. Hypertension 29: 1025-1030.

19. Nussberger J (2000) Circulating versus tissue angiotensin II. In Angiotensin II receptor antagonists. Edited by Murray Epstein, Hans Brunner Philadelphia: Hanley \& Belfus: 69-78.

20. Tham DM, Martin-McNulty B, Wang YX, Wilson DW, Vergona R, et al. (2002) Angiotensin II is associated with activation of NF-kappaB-mediated genes and downregulation of PPARs. Physiol Genomics 11: 21-30.

21. Recinos A 3rd, LeJeune WS, Sun H, Lee CY, Tieu BC, et al. (2007) Angiotensin II induces IL-6 expression and the Jak-STAT3 pathway in aortic adventitia of LDL receptor-deficient mice. Atherosclerosis 194: 125-133.

22. Yang LX, Yang ZH, Guo RW, Ye JS, Liu H (2012) Angiotensin II induces extracellular matrix metalloproteinase inducer expression via an AT1R dependent pathway in aortic atherosclerotic plaque in apolipoprotein $E$ knockout mice. JRAAS 13: 67-75.

23. Owens AP 3rd, Rateri DL, Howatt DA, Moore KJ, Tobias PS, et al. (2011) MyD88 deficiency attenuates angiotensin II-induced abdominal aortic aneurysm formation independent of signaling through Toll-like receptors 2 and 4. Arterioscler Thromb Vasc Biol 31: 2813-2819.

24. Suen RS, Rampersad SN, Stewart DJ, Courtman DW (2011) Differential roles of endothelin-1 in angiotensin II-induced atherosclerosis and aortic aneurysms in apolipoprotein E-null mice. Am J Pathol 179: 1549-1559.

25. Wang S, Subramanian V, Lu H, Howatt DA, Moorleghen JJ, et al. (2012) Deficiency of receptor-associated protein attenuates angiotensin II-induced atherosclerosis in hypercholesterolemic mice without influencing abdominal aortic aneurysms. Atherosclerosis 220: 375-80.

26. Seto SW, Krishna SM, Yu H, Liu D, Khosla S, et al. (2013) Impaired acetylcholine-induced endothelium-dependent aortic relaxation by caveolin-1 in angiotensin II-infused apolipoprotein-E (ApoE-/-) knockout mice. PLoS One 8: e58481.

27. Liu XH, Ji QW, Huang Y, Zeng QT (2011) Th17 response promotes angiotensin II-induced atherosclerosis. Med Hypotheses 76: 593-595.

28. Hoeksema MA, Stoger JL, de Winther MP (2012) Molecular pathways regulating macrophage polarization: implications for atherosclerosis. Curr Atheroscler Rep 14: 254-263. 